\title{
Degree of Control and Main Complications of Hyperthyroid Pregnant Women in a Real Life Experience with Methimazol
}

\author{
Díaz Arizmendi Diana Elizabeth ${ }^{1}$, Mendieta Zerón Hugo ${ }^{1,2, *}$ \\ ${ }^{1}$ Faculty of Medicine, Autonomous University of the State of Mexico, Toluca, Mexico \\ ${ }^{2}$ Research Department, "Mónica Pretelini Sáenz" Maternal-Perinatal Hospital (HMPMPS) and Ciprés Grupo Médico (CGM), Toluca, \\ Mexico
}

Email address:

dian.diaz@hotmail.com (D. A. D. Elizabeth),drmendietaz@yahoo.com (M. Z. Hugo)

${ }^{*}$ Corresponding author

\section{To cite this article:}

Díaz Arizmendi Diana Elizabeth, Mendieta Zerón Hugo. Degree of Control and Main Complications of Hyperthyroid Pregnant Women in a Real Life Experience with Methimazol. American Journal of Internal Medicine. Special Issue: Thyroid in Systemic Diseases.

Vol. 8, No. 1, 2020, pp. 19-23. doi: 10.11648/j.ajim.20200801.14

Received: December 27, 2019; Accepted: January 6, 2020; Published: January 13, 2020

\begin{abstract}
Hyperthyroidism is one of the main endocrinopathies during pregnancy. The aim of this project was to identify the degree of control of hyperthyroid pregnant women based on the recommendations of the American Thyroid Association (ATA) in a real situation without the availability of propylthiouracil. This was a descriptive, retrospective and longitudinal study, including medical files of pregnant women with hyperthyroidism between 18 and 35 years. They were classified as having "Adequate" control if their thyroid profiles were within the recommendations of the ATA and had no adrenergic symptoms; and were categorized as having "Inadequate" control if they were not stabilized with monotherapy, or if they required high doses of antithyroid drugs or beta-blockers or showed serious complications including the need of an Intensive Care Unit (ICU) for mothers or neonates. The Chi square test was performed between treatment groups during the third trimester and the complications of pregnant women or neonates. A total of 173 hyperthyroid pregnant women were studied with an average age of $21 \pm 4.7$ years. Of the 33 patients with hyperthyroidism who received monotherapy with methimazole until the end of pregnancy, 23 (69.69\%) were classified as having "Adequate" control. In a real life situation there is delay in the diagnosis of hyperthyroidism during pregnancy but even without propylthiuracil, an "Adequate" control can be reached in up to $20.53 \%$ of cases based on a methimazole monotherapy.
\end{abstract}

Keywords: Degree of Control, Hyperthyroidism, Methimazole, Pregnancy, Propranolol

\section{Introduction}

Hyperthyroidism is the second most common thyroid disease during pregnancy, with an incidence ranging from 0.1 to $0.4 \%$ [1]. The most frequent cause of hyperthyroidism in pregnancy is Graves' disease (85-90\% of cases) [2]. Among other causes are simple toxic adenoma, multinodular toxic goiter and thyroiditis, in addition to considering the cases of transient gestational thyrotoxicosis [3]. The diagnosis of this entity is usually a challenge for doctors in its initial phase due to the physiological changes of pregnancy [4].

The treatment options for hyperthyroidism are propylthiouracil (PTU), methimazole and carbimazole; occasionally it is recommended to add beta-blockers and subtotal thyroidectomy is reserved for specific cases [5].

Both PTU and methimazole may be associated with adverse events in embryological development [6]. However, the first is the drug of choice during the first trimester of pregnancy $[7,8]$ with the recommended initial dose of 200 to $400 \mathrm{mg}$ /day divided into three doses, while for methimazole it is 20 to $30 \mathrm{mg} /$ day divided into two doses [9]. Improvement is usually observed within a week, however, it may take 4 to 6 weeks to get the full effect. Unfortunately PTU is not available in several countries.

Beta-blockers are useful for controlling tachycardia or palpitations, although it is preferable to give short periods of treatment and even avoid their use due to increased chances of cardiovascular defects, cleft lip/palate and neural tube defects [10], although more recent studies with a large 
number of patients do not confirm an increased risk of complications with these drugs [11].

The aim of this study was to describe the degree of control of hyperthyroid pregnant women treated with methimazole and to describe the main complications associated with its use.

\section{Method}

\subsection{Setting}

This descriptive, retrospective and longitudinal study was conducted at the "Mónica Pretelini Sáenz" Maternal-Perinatal Hospital (HMPMPS), Health Institute of the State of Mexico (ISEM), Toluca, Mexico.

\subsection{Patients}

The information was obtained from the clinical files and from the electronic data of the Department of Statistics. The inclusion criteria were: hyperthyroid pregnant women aged between 18 and 35 years who attended in the period 20102016. Hyperthyroid patients with another accompanying comorbidity, who ingested antidepressants/antipsychotics or with abandonment of treatment or termination of pregnancy in another institution, were excluded.

For the calculation of Body Mass Index $\left(B M I=\mathrm{kg} / \mathrm{m}^{2}\right)$, weight and height data were taken during the initial stage of pregnancy. Patients were classified as having "Adequate" control if their thyroid profiles were within the recommendations of the American Thyroid Association (ATA) for pregnant women without adrenergic symptoms, and were categorized as having "Inadequate" control if they were difficult to control based on monotherapy, if they required high doses of antithyroid drugs or beta-blockers or if mothers or neonates had serious complications, including admission to the Intensive Care Unit (ICU).

\subsection{Statistical Analysis}

The information was recorded in an Excel sheet, and measures of central tendency were calculated for the quantitative variables; for the qualitative variables, frequencies and percentages were used. Chi square test was performed between treatment groups during the third trimester and the complications of pregnant women and neonates. A p-value of less than 0.05 was considered statistically significant using the IBM SPSS Statistics 23.0 .

\subsection{Ethical Standards}

This study was approved by the Research and Research Ethics Committees of the HMPMPS (code 2016-09-479). This was considered a no-risk study, which followed the regulations of the Mexican General Health Law in Matters of Research and complied with the standards of the Declaration of Helsinki (updated in Fortaleza, Brazil, 2013).

\section{Results}

We studied a total of 173 hyperthyroid pregnant women who met the criteria. The mean age was $21 \pm 4.7$ years, weight $79 \pm 3.9 \mathrm{~kg}$ and height $1.56 \pm 0.02 \mathrm{~cm}$. According to the BMI classification, the following data were obtained: Overweight: $18(10.40 \%)$ patients, Obesity grade I: 136 (78.61\%) and Obesity grade II: 19 (10.98\%).

Table 1 shows the thyroid-stimulating hormone (TSH), triiodothyronine (T3) and thyroxine (T4) values obtained per trimester. When calculating the 2.5 and 97.5 percentiles of $\mathrm{TSH}$, the values per trimester were: $0.04-2.79 \mathrm{mU} / \mathrm{L}, 0.032$ $3.93 \mathrm{mU} / \mathrm{L}$, and $0.008-2.804 \mathrm{mU} / \mathrm{L}$.

Table 1. Values of thyroid hormones per trimester.

\begin{tabular}{llllll}
\hline & Trimester & Mean & Median & Mode & $\begin{array}{l}\text { Standard } \\
\text { Deviation }\end{array}$ \\
\hline TSH (mU/L) & First $_{1}$ & 1.21 & 1.03 & 0.97 & 0.77 \\
& Second $_{2}$ & 1.68 & 1.55 & 0.89 & 1.19 \\
& Third $_{3}$ & 1.21 & 1.15 & 0.89 & 0.78 \\
Free T4 (ng/dl) & First $_{1}$ & 1.59 & 1.38 & 1.23 & 0.82 \\
& Second $_{2}$ & 4.25 & 4.33 & 4.56 & 0.81 \\
& Third $_{3}$ & 2.47 & 1.66 & 1.23 & 1.42 \\
Free T3 (pg/ml) & First $_{1}$ & 3.59 & 3.6 & 3.44 & 0.78 \\
& Second $_{2}$ & 3.48 & 3.53 & 3.01 & 0.84 \\
& Third $_{3}$ & 3.68 & 3.47 & 3.45 & 0.96 \\
\hline
\end{tabular}

${ }_{1}$ First trimester: 0-12 weeks of gestation.

${ }_{2}$ Second trimester: $13-28$ weeks of gestation

${ }_{3}$ Third trimester: $29-40$ weeks of gestation.

Only $26(15.02 \%)$ pregnant women were diagnosed with hyperthyroidism during the first trimester. From this initial number of cases, $17(65.38 \%)$ were in treatment with methimazole + propranolol of which the most frequent doses were $45 \mathrm{mg} / 24 \mathrm{~h}$ of the first and $40 \mathrm{mg} / 24 \mathrm{~h}$ of the second divided into three doses, while nine (34.61\%) received monotherapy with propranolol at a dose of $40 \mathrm{mg} / 24 \mathrm{~h}$.

During the second trimester, all the 173 pregnant women were diagnosed with hyperthyroidism. At this cut-off point the most frequent treatment option was methimazole as monotherapy, used in $112(64.7 \%)$ of the pregnant women, with the most frequent doses being $30 \mathrm{mg} / 24 \mathrm{~h}$ in $30(17.34 \%)$ patients, and $40 \mathrm{mg} / 24 \mathrm{~h}$ in $29(16.76 \%)$ patients; $20 \mathrm{mg} / 24 \mathrm{~h}$ was prescribed only in $20(11.56 \%)$ patients and often less, other doses.

Of the 112 patients on monotherapy with methimazole during the second trimester, an adjustment to methimazole/metoprolol in $27(24.10 \%)$ patients and methimazole/propranolol in $52(46.42 \%)$ was documented. Only $33(29.46 \%)$ continued with methimazole monotherapy until the end of pregnancy, most of them requiring a dose increase in the third trimester of up to $50 \mathrm{mg} / 24 \mathrm{~h}$; from this subgroup, 23 (69.69\%) were classified as having "Adequate" control and $10(30.30 \%)$ as "Inadequate" control. Maternal complications were uterine atony in three patients, and others were premature rupture of membranes, preeclampsia, and admission to the ICU. For the neonates the most common complications were neonatal sepsis, fetal tachycardia and low weight for gestational age. 
Only $13(7.5 \%)$ women were treated with propranolol monotherapy at a dose of $80 \mathrm{mg} / 24 \mathrm{~h}$ in 10 of them and 40 $\mathrm{mg} / 24 \mathrm{~h}$ in three. Two pregnant women continued with propranolol at a dose of $80 \mathrm{mg} / 24 \mathrm{~h}-20 \mathrm{mg} / 24 \mathrm{~h}$, highlighting the finding that both had premature rupture of membranes. Eight patients who started on monotherapy with propranolol, changed the drug to methimazole monotherapy at a dose of $40 \mathrm{mg} / 24 \mathrm{~h}$, and three were admitted to the ICU. Three patients who started propranolol monotherapy finished gestation with two-drug therapy: methimazole/metoprolol in doses of $20 \mathrm{mg} / 24 \mathrm{~h} \quad-60 \quad \mathrm{mg} / 24 \mathrm{~h}$ and methimazole/propranolol in doses of $45 \mathrm{mg} / 24 \mathrm{~h}-40 \mathrm{mg} / 24 \mathrm{~h}$ with unfavorable results.

Of the patients under treatment with methimazole, there were five cases of each of the following complications: admission to the ICU, preeclampsia and uterine atony; the others (23) had no complications. 28 of the neonates had no complications, but 13 had low weight for gestational age. Of the pregnant women with treatment based on methimazole/metoprolol, seven were admitted to the ICU, four developed gestational diabetes and two had preeclampsia. Of the pregnant women with treatment based on methimazole/propranolol, 13 developed preeclampsia and 11 were admitted to the ICU.

During the third trimester the different treatments did not have an important significance with the degree of control obtained. In that trimester, of a total of 81 patients on treatment with methimazole/propranolol 48 achieved the TSH ranges of the ATA.

Within the full population and in decreasing order, the complications were preeclampsia: $11.6 \%$, uterine atony: $9.2 \%$, premature rupture of membranes: $6.9 \%$, gestational diabetes: $6.4 \%$ and abdominal resolution: $5.8 \%$. Caesarean section resolution is not considered a complication, however, most of the times it was preceded by complications such as premature rupture of membranes, oligohydramnios, and fetal distress, among others.

With regard to neonates, the most frequent complications were the following: low weight for gestational age in 24 (13.9\%); neonatal sepsis in $9.8 \%$ with predominantly a pulmonary focus; prematurity in $9.2 \%$, reported as late preterm (34-36.6 weeks of gestation according to the WHO) in most of them, fetal tachycardia in $6.4 \%$, cardiac pathology in $5.2 \%$, severe oligohydramnios (amniotic fluid index $<5 \mathrm{~cm}$ according to Phelan) in $4.6 \%$; admission to the ICU in $2.3 \%$, and stillbirth in one unfortunate case.

A Chi square test was performed between treatment groups during the third trimester without finding significant differences when comparing the groups, inferring that the treatment used during the third trimester influences neither the complications of pregnant women nor in newborns.

\section{Discussion}

Generally speaking, our population reflects a problem in Mexico with a tendency for pregnancies in adolescents; in fact, most of our patients were already secundigravidas or even multigravidas [12], and the majority of them during the first trimester had a BMI classified as Obesity grade I, remembering that Mexico ranks in the first positions for obesity [13]. Both conditions increase the risk of complications $[12,14]$.

Currently, despite the fact that hyperthyroidism constitutes a challenge for clinical diagnosis due to the masked symptoms of pregnancy itself [15], in several countries, including Mexico, the determination of thyroid hormones in pregnant women is not included in the prenatal control. This a critical issue to be attended to and even more so during the first trimester since in this period the fetus depends on the maternal hormones [16].

In our study, TSH values less than $0.2 \mathrm{mU} / \mathrm{L}$ belonged to pregnant women who had already been diagnosed with hyperthyroidism during the first trimester, and those with values greater than $2.5 \mathrm{mU} / \mathrm{L}$ (13 women) never presented adequate values, despite treatment in high doses. The values of T4, compared with the reference values of the HMPMPS laboratory were totally out of range, with extremely high values, even more than those described in several international studies $[17,18]$. In the case of $\mathrm{T} 3$, the values obtained were very similar to the limits of the reference laboratory.

It was also found in the population studied, that during the second trimester, the behavior of the thyroid hormones was above those of the laboratory of reference. Thus, according to the values of thyroid function during the second trimester, showing in general a higher decontrol required higher doses of monotherapy or the use of a two-drug therapy. In the third trimester, a behavior like that described in the two previous trimesters was observed, with very high T4L values, which speak to us of a control much lower than expected in this period.

The reference values of thyroid hormones in the general population are not similar to those of the pregnant women [19]. The above, in clinical practice, can lead to results misinterpretation, so it is convenient to define the values of thyroid hormones in the population of pregnant women in each trimester and for each area of origin, to make an early and correct diagnosis and to offer the best treatment. It must be emphasized that failure to diagnose thyroid disease in a timely manner may clinically manifest as a thyrotoxicosis with potential life risk for the maternal-fetal binomial [20].

Finally, it is noteworthy that "Adequate" control was achieved in $20.53 \%$ of cases based on an initial methimazole monotherapy of 112 patients starting this treatment in the second trimester of pregnancy. Furthermore, although the European and American guidelines mention that the thyroid control of pregnant women should be carried out every 2 to 6 weeks [21], this is impossible in the case of health institutions that serve a very low socioeconomic level population.

A matter of great concern is the risk of embryopathies with either option, propylthiouracil or methimazole, widely reported in the literature $[22,23]$. Although this project was not designed to get either odds ratio or relative risk 
calculations of cardiac anomalies while using methimazole, the presence of a cardiac pathology in $5.2 \%$ of the newborns of the full sample could reflect a trend of a higher rate of congenital cardiac defects than that reported for the same population of 7.4 per 1,000 live births (35.6 per 1,000 in preterm infants and 3.68 per 1,000 in term newborns) [24].

Our results prove that the focus, to avoid pregnancy complications in cases of hyperthyroidism, must be on the preconception orientation, offering to future mothers who have the diagnosis of hyperthyroidism to receive at least six months before pregnancy a dose of radioactive iodine to convert them into hypothyroidism, which has less risks to the mother and the fetus [25].

A limitation of this study is that there may be an underdiagnoses of hyperthyroidism cases, since in the electronic file of the Department of Statistics this diagnosis may not have been registered if the patient entered the hospital for another reason.

Two main conclusions are obtained based on the results of this study. First, the cases of hyperthyroidism that debut in pregnancy are still delayed in the diagnosis during the first trimester. Second, in a real life situation "Adequate" control can be reached in only $13.29 \%$ of hyperthyroidism cases during pregnancy based on a methimazole monotherapy.

\section{Author Contributions}

DADE collected the data. DADE and MZH analyzed the data and wrote the first draft. Both authors agreed on the final draft submitted for consideration.

\section{Conflict of Interests}

The authors declare that there is no conflict of interest in relation to the content of the manuscript.

\section{Acknowledgements}

To the Clinical Archive of the "Mónica Pretelini Sáenz" Maternal Perinatal Hospital for its facilities to collect the analysis files.

\section{References}

[1] Ahmad S, Geraci SA, Koch CA. Thyroid disease in pregnancy: (Women's Health Series). South Med J 2013; 106: 532-8.

[2] Bucci I, Giuliani C, Napolitano G. Thyroid-Stimulating Hormone Receptor Antibodies in Pregnancy: Clinical Relevance. Front Endocrinol 2017; 8: 137.

[3] King JR, Lachica R, Lee RH, et al. Diagnosis and Management of Hyperthyroidism in Pregnancy: A Review. Obstet Gynecol Surv 2016; 71: 675-85.

[4] May L. Cardiac Physiology of Pregnancy. Compr Physiol 2015; 5: 1325-44.
[5] Cooper DS, Laurberg P. Hyperthyroidism in pregnancy. Lancet Diabetes Endocrinol 2013; 1: 238-49.

[6] Mallela MK, Strobl M, Poulsen RR, et al. Evaluation of developmental toxicity of propylthiouracil and methimazole. Birth Defects Res B Dev Reprod Toxicol 2014; 101: 300-7.

[7] Khan I, Okosieme O, Lazarus J. Antithyroid drug therapy in pregnancy: a review of guideline recommendations. Expert Rev Endocrinol Metab 2017; 12: 269-78.

[8] Andersen SL, Laurberg P. Managing hyperthyroidism in pregnancy: current perspectives. Int J Womens Health 2016; 8: 497-504.

[9] Fumarola A, Di Fiore A, Dainelli M, et al. Therapy of hyperthyroidism in pregnancy and breastfeeding. Obstet Gynecol Surv 2011; 66: 378-685.

[10] Yakoob MY, Bateman BT, Ho E, et al. The risk of congenital malformations associated with exposure to $\beta$-blockers early in pregnancy: a meta-analysis. Hypertension 2013; 62: 375-81.

[11] Bergman JEH, Lutke LR, Gans ROB, et al. Beta-Blocker Use in Pregnancy and Risk of Specific Congenital Anomalies: A European Case-Malformed Control Study. Drug Saf 2018; 41: 415-27.

[12] Villalobos-Hernández A, Campero L, Suárez-López L, et al. [Teen pregnancy and educational gaps: Analysis of a national survey in Mexico]. Salud Publica Mex 2015; 57: 135-43.

[13] OCDE. Overweight \& Obesity [Internet]. Disponible en: https://www.oecd.org/centrodemexico/estadisticas/.

[14] Marchi J, Berg M, Dencker A, et al. Risks associated with obesity in pregnancy, for the mother and baby: a systematic review of reviews. Obes Rev 2015; 16: 621-38.

[15] Iwen KA, Lehnert H. [Thyroid and pregnancy]. Internist 2018; 59: 654-60.

[16] Abalovich MS. Fisiología tiroidea y embarazo. Aspectos maternos, placentarios y fetales. Rev Argent Endocrinol Metab 2003; 40: 23-31.

[17] Alexander EK, Pearce EN, Brent GA, et al. 2017 Guidelines of the American Thyroid Association for the Diagnosis and Management of Thyroid Disease During Pregnancy and the Postpartum. Thyroid 2017; 27: 315-89.

[18] Santiago P, Berrio M, Olmedo P, et al. Valores de referencia de hormonas tiroideas en la población de mujeres gestantes de Jaén. Endocrinol Nutr 2011; 58: 62-7.

[19] Wei Q, Zhang L, Liu XX, et al. [Clinical analysis of the specific reference intervals of thyroid index for normal pregnant women]. Zhonghua Fu Chan Ke Za Zhi 2018; 53: 299-303.

[20] Rivera ZR, Aguilera TJ, Larraín HA. Epidemiología del virus papiloma humano (HPV). Rev Chil Obstet Ginecol 2002; 67: 501-6.

[21] Poppe K, Hubalewska-Dydejczyk A, Laurberg P, et al. Management of Hyperthyroidism in Pregnancy: Results of a Survey among Members of the European Thyroid Association. Eur Thyroid J 2012; 1: 34-40.

[22] Clementi M, Di Gianantonio E, Cassina M, et al; SAFE-Med Study Group. Treatment of hyperthyroidism in pregnancy and birth defects. J Clin Endocrinol Metab 2010; 95: E337-E341. 
[23] Andersen SL, Olsen J, Wu CS, et al. Birth defects after early pregnancy use of antithyroid drugs: a Danish nationwide study. J Clin Endocrinol Metab 2013; 98: 4373-81.

[24] Mendieta-Alcántara GG, Santiago-Alcántara E, MendietaZerón $\mathrm{H}$, et al. [Incidence of congenital heart disease and factors associated with mortality in children born in two Hospitals in the State of Mexico]. Gac Med Mex 2013; 149: 617-23.

[25] Teng W, Shan Z, Patil-Sisodia K, et al. Hypothyroidism in pregnancy. Lancet Diabetes Endocrinol 2013; 1: 228-37. 